\title{
P94 Relationship Between Central Pressure and Potassium Urinary Excretion in a Population-Based Study in Salvador, Brazil, Preliminary Results
}

\author{
Antonio Filho ${ }^{1, *}$, Lucélia Magalhães ${ }^{1}$, Danielle Brustolim ${ }^{1}$, Diorlene da Silva ${ }^{1}$, Roberta de Castro ${ }^{1}$, Larissa Bessa ${ }^{1}$, \\ VASCOR grupo VASCOR ${ }^{1}$
}

${ }^{1}$ Faculdade de Tecnologia e Ciências, Salvador, Brazil

\begin{abstract}
Introduction: Central pressure (CP) has been shown to be more reliable in cardiovascular mortality than peripheral. Previous studies correlate the relationship between $\mathrm{CP}$ increase and urinary potassium excretion.

Methods: A population-based cross-sectional study representative of a neighborhood of Salvador-Ba, Brazil, distributed in 12 census tracts according to the Brazilian Institute of Geography and Statistics. The overall sample is randomized in adults from the assigned area from December 2016 to May 2019. Individual and household records are filled out. The CP, measured in the radial artery, obtained through aplanation tonometry, using the SphygmoCor apparatus (XCEL, AtCor Medical, Sydney, Australia, [2] with confidence $\geq 85 \%$ ). CP is evaluated directly by the central systolic pressure equipment and central diastolic blood pressures collected, blood and urine of 24 hours of urinary potassium were quantified by the ADVIA $1800^{\circ}$ selective ion electrode (SiemensHealthcare Japan/Canada). All participants signed a Free and Informed Consent Form. Frequency and descriptive measures (mean, standard deviation), Spearman's linear correlation coefficient between $\mathrm{CP}$ and $\mathrm{K}^{+}$were stratified by age and sex, using STATA v.12 software for treatment and generation of results, and the level of statistical significance of $5 \%$.

Results: A total of 145 individuals with a predominance of females (70.3\%). The CP and excretion of potassium in the female sex was directly proportional, whereas in the male sex the ratio was inversely proportional, but in both groups there wasn't statistical significance.
\end{abstract}

Conclusion: The results obtained weren't adequate for the literature. A larger sample is needed for accuracy in this group.

\section{REFERENCES}

[1] Pini R, Cavallini MC, Palmieri V, Marchionni N, Di Bari M, Devereux RB, et al. Central but not brachial blood pressure predicts cardiovascular events in an unselected geriatric population: the ICARe Dicomano Study. J Am Coll Cardiol 2008;51:2432-9.

[2] Kollias A, Lagou S, Zeniodi ME, Boubouchairopoulou N, Stergiou GS. Association of central versus brachial blood pressure with target-organ damage: systematic review and meta-analysis. Hypertension 2016;67:183-90.

[3] Gates PE, Tanaka H, Hiatt WR, Seals DR. Dietary sodium restriction rapidly improves large elastic artery compliance in older adults with systolic hypertension. Hypertension 2004;44:35-41.

(C) 2019 Association for Research into Arterial Structure and Physiology. Publishing services by Atlantis Press International B.V. This is an open access article distributed under the CC BY-NC 4.0 license (http://creativecommons.org/licenses/by-nc/4.0/). 